\title{
A pesquisa: areais e arenização, o ponto de partida para uma reflexão em Geografia
}

The research: sand deposits and arenization, the starting point for a reflection in Geography

\section{Dirce Maria Antunes Suertegaray '}

\section{RESUMO}

Este texto resgata a produção do conhecimento sobre areais e sobre arenização, a partir da leitura de como se processou a pesquisa sobre o tema, ao longo de mais de 30 anos, e faz uma reflexão, considerando, de um lado, as questões que norteiam a pesquisa e, de outro, os conceitos que foram sendo construídos e/ou ressignificados, na sua relação com a Geografia. Assenta-se na narrativa e na reflexão teórica sobre arenização, pesquisa e conceitos de análise.

Palavras-chaves: Arenização; Areais do Sudoeste do RS; Pesquisa geográfica

\section{ABSTRACT}

This text recovers the production of knowledge about sand deposits and arenization processes, from the reading of how the research on these topics was made, over the past 30 years, and makes a reflection, considering, on the one hand, the issues that have guided the research and, on the other, the concepts that have been constructed and / or redefined, considering their relation to Geography. It is based on narrative and theoretical reflections on arenization, through research and concepts analysis.

Keywords: Arenization; Sand deposits of Southwestern RS; Geographic research 


\section{RESUMEN}

Este texto rescata la producción de conocimiento sobre arenales y arenización, a partir de la lectura de cómo se procesó la investigación sobre estos temas, durante los últimos 30 años, y hace una reflexión, considerando, por un lado, los temas que han guiado la investigación y, por otro lado, los conceptos que se estaban construyendo y / o siendo reformulados, en su relación con la Geografía. Se basa en la reflexión narrativa y teórica sobre la arenización, por medio de investigación y análisis.

Palabras-clave: Arenización; Arenales del suroeste de RS; Búsqueda geográfica

\section{INTRODUÇÃO}

Neste texto, tem-se o objetivo de construir uma narrativa e uma reflexão teórica que associe o processo de pesquisa, em relação às questões que nos são indicadas como pressupostos de uma investigação, e os conceitos que foram se delineando, ao logo destes mais de 30 anos de atividade investigativa, na Geomorfologia/Geografia.

Parte-se das questões que orientam uma pesquisa e, a partir da resolução dessas questões, é feita uma reflexão sobre categorias e sobre conceitos que norteiam o processo. Dito de outra forma, busca-se, aqui, expressar o sentido da pesquisa, tomando, como referência, as seguintes questões: o que pesquisar? por que pesquisar? como pesquisar? para quem pesquisar? e com quem pesquisar?

A inspiração que norteou o início do processo de investigação sobre os areais, no Sudoeste (SW) do Rio Grande do Sul (RS) vincula-se ao contexto dos anos 1980, década de grande efervescência da discussão ambiental e do surgimento das organizações ambientais. Neste momento, emerge a descoberta e a discussão relativas aos areais do Sudoeste do Rio Grande do Sul (RS). Os primeiros estudos vinculam-se à SUDESUL, ao IBGE e à produção bibliográfica de Souto (1985), 
engenheiro agrônomo, vinculado à Secretaria da Agricultura do Estado do RS. Particularmente, merece destaque este último trabalho, uma vez que foi a partir dele que se divulgou uma perspectiva interpretativa, vinculando os areais (denominação reconhecida pelos moradores locais) a desertos e ao(s) processo(s) que estaria(m) originando a desertificação.

Associava-se, a essa leitura, uma questão ambiental, na medida em que a origem dessas feições foi atribuída à expansão da agricultura comercial, sobretudo, a expansão do plantio de soja. Esta atividade agrícola, desde aquela época, vem expandindo-se das áreas consagradas de plantio, na região do Planalto do Rio Grande do Sul, em direção ao Sudoeste e ocupando, através de arrendamento, terras historicamente pastoris da fronteira Sudoeste do RS, é apontada como a causa da desertificação.

\section{O PROCESSO DE INVESTIGAÇÃO}

A inspiração inicial e a escolha de O QUE estudar, por sua vez, expressa questões vinculadas à Geografia. Em especial, no que se refere à possibilidade de um estudo que permitisse a articulação sociedade-natureza, buscando-se decifrar esse fenômeno, no âmbito da questão ambiental. Buscar um tema que permitisse a vinculação entre natureza e sociedade constituiu a questão analítica central, considerando que a análise, partindo de estudos geomorfológicos, pretendia responder sobre a gênese dos areais. Ou seja, a pergunta inicial e o processo de investigação centravam-se no seguinte questionamento: a origem dos areais do Sudoeste do RS é natural ou antrópica?

Definido o que estudar, enquanto tema e construída a pergunta que desencadearia o processo de pesquisa, na continuidade, caberia fazer a escolha da área de ocorrência desse fenômeno. A área escolhida corresponde ao distrito com presença de areais, no município de Quaraí/RS. 
Figura 1 - Localização dos areais, no município de Quaraí-RS

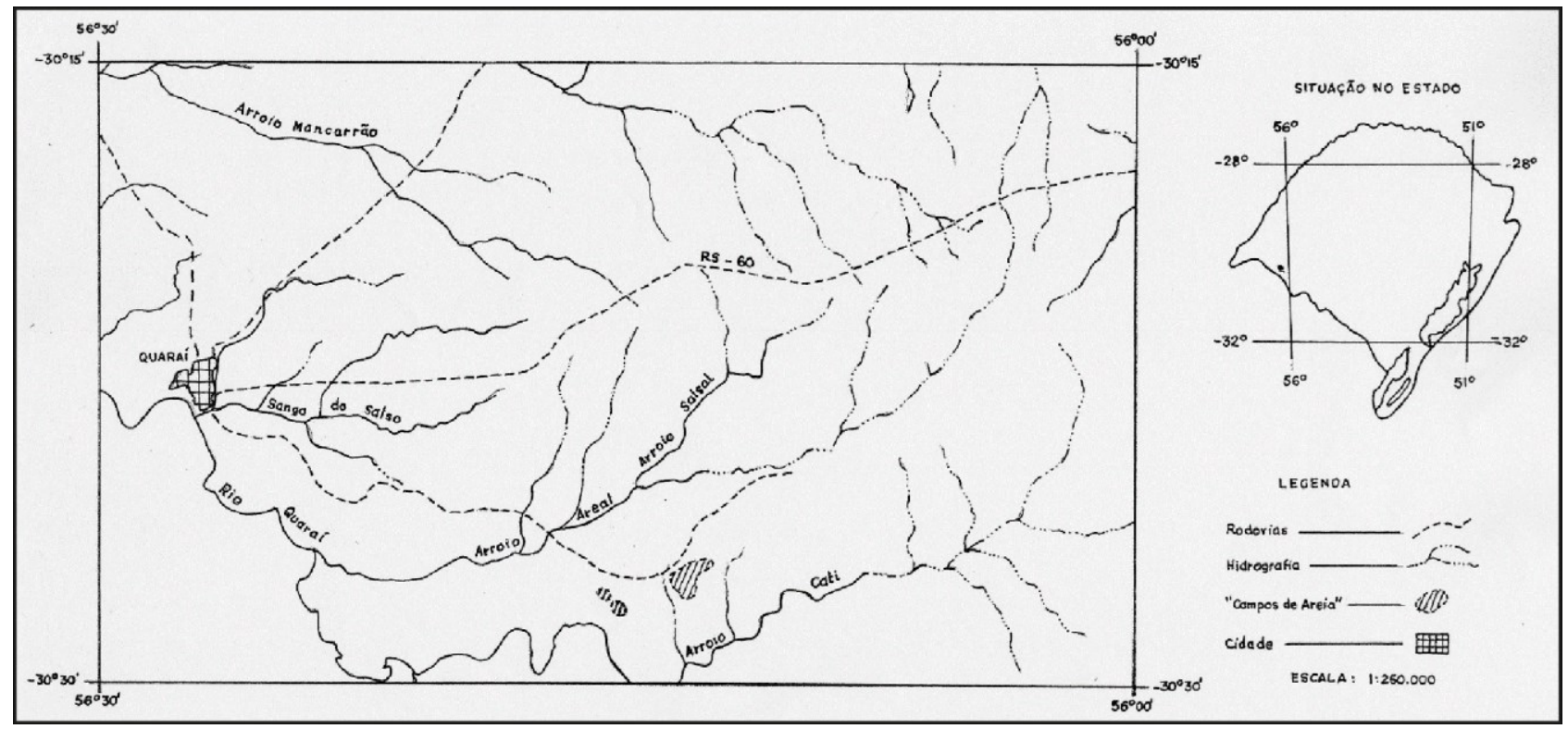

Fonte: Suertegaray (1987).

As justificativas de POR QUE estudar os areais, em certa medida, já foram apresentadas, anteriormente. Entretanto, explicitando um pouco mais, pode-se dizer que esta escolha se deveu ao fato de que, pelo que vinha sendo divulgado, sobretudo, na imprensa, este tema apresentava os requisitos para um estudo de interface natureza e sociedade, interesse central de quem se iniciava nesses estudos. Da mesma forma, justificava-se pela possibilidade de contribuir com a sociedade gaúcha sobre a explicitação da gênese deste processo, de sua distribuição, de sua extensão e de possibilidades de reconstituição do antigo ambiente.

Imbricado, nesta questão, tem-se pela frente a construção do caminho analítico - o Método. Depara-se, neste momento, com a necessidade de aprofundamento teórico-conceitual norteador da investigação.

Um dos primeiros conceitos a serem avaliados constituiu o conceito de desertificação. Uma questão que se colocava é o que é desertificação? E, na sequência, avaliou-se que esse conceito não respondeu como uma possível explicação do que viria a ser investigado.

Uma outra dimensão a ser tratada era como construir uma leitura analítica da conexão entre natureza e sociedade. Nesse sentido, foi necessário, não só, um resgate da construção histórica da Geografia, no sentido de justificar a pertinência do 
tema, mas, também, explicitar quais eram as tendências metodológicas difundidas, na época, que poderiam dar conta da análise proposta.

Neste percurso, surge como emergente, em termos de abordagem metodológica, o conceito de sistema. A busca de entendimento do que seria um sistema, como se expressa e o que uma análise sistêmica permite avaliar não contemplava a questão construída para investigação. O desejado, neste processo investigativo, era mais amplo do que aquilo que a análise sistêmica poderia oferecer, ou seja, a compreensão da funcionalidade de um dado fenômeno, entendido, este, como um conjunto de elementos em interação.

Para o propósito da tese a ser construída, este conceito era limitante, na medida em que permitiria abordar a funcionalidade do sistema objeto de estudo, sem, contudo, dar conta da explicação da questão proposta. Ao seguir este caminho, não seria possível responder à pergunta inicial sobre a gênese dos areais. Tal resposta exigia uma compreensão do processo histórico de formação dessas áreas, para que fosse possível avaliar se as áreas de ocorrência de areais, sobretudo, em Quaraí, eram de origem natural ou social.

A resposta a esta pergunta, aparentemente, simples exigia um caminho no qual se considerasse a historicidade, neste caso específico, da natureza e da sociedade em conexão.

A discussão, na época, vinculada à classificação científica vigente, que separava as dimensões natureza e sociedade, se fazia, fortemente, no interior da discussão geográfica. Sobretudo, a partir do movimento da Geografia Crítica, de perspectiva dialética e materialista - o Materialismo Histórico, tornava essa possibilidade inviável, uma vez que, em Marx, a natureza não era num contexto social originalmente natural, ou seja, seria concebida como segunda natureza, transformada pelo trabalho humano.

De qualquer forma, foi em Marx e Engels que se encontrou o pressuposto que encaminhou a investigação sobre a gênese dos areais, ou seja, foi na síntese marxista, expressa em Marx e Engels (1977). Nesta obra, estes concebem a existência de uma única ciência, a ciência da história. Esta poderia ser contada como história natural ou 
historial social. Não obstante, ao contar a história social, seria imprescindível considerar que o processo de socialização do homem constitui, concomitantemente, um processo de socialização da natureza e, neste processo, a natureza natural, através do trabalho humano, se constituiria em segunda natureza.

Esta formulação abriu caminho para uma investigação centrada em dois eixos: o da natureza e o da sociedade (Figura 2). Para a construção da investigação, no contexto da natureza, o conceito geográfico escolhido foi o da Paisagem, enquanto conjunto de elementos naturais. Nesta perspectiva, a investigação parte, inicialmente, do arcabouço da geomorfologia (lógica formal) para buscar decifrar a origem da paisagem e sua transformação, no tempo. Neste caso, a escala adotada foi a escala geológica, e o objetivo era resgatar a história natural da paisagem em análise, objetivando avaliar a presença de areais, em tempos mais remotos, que pudessem constituir elementos de decifração de sua origem.

O segundo eixo, a dimensão social, toma como referência o conceito de Território, enquanto Estado-Nação. Buscou-se, então, compreender a inserção da região de ocorrência de areais, a fronteira Sudoeste do RS, no processo de formação econômica social do Brasil. Para tanto, o fundamento da análise foi baseado no processo de ocupação desta parcela de espaço natural (paisagem natural), no período histórico de sua inserção, na conformação do território brasileiro, no período Imperial, e na sua continuidade, até o momento de investigação, entre os anos de 1983 e 1987, quando a tese em elaboração foi concluída.

Este eixo privilegiou a História, em seu movimento, o que se denominou escala histórica de análise. Uma ressalva deve ser feita: esta escala pode ser entendida como escala histórico-geográfica, sugestão dada pelos avaliadores, à época, e que se considerou relevante, considerando a indissociabilidade do espaço-tempo.

A articulação entre esses dois eixos foi construída, a partir da busca de compreensão da apropriação da natureza, a partir da categoria marxista de trabalho. Nos escritos de Marx, a transformação da natureza em natureza social se faz pela mediação do trabalho humano. 
Figura 2 - Fluxograma da investigação sobre os areais de Quaraí

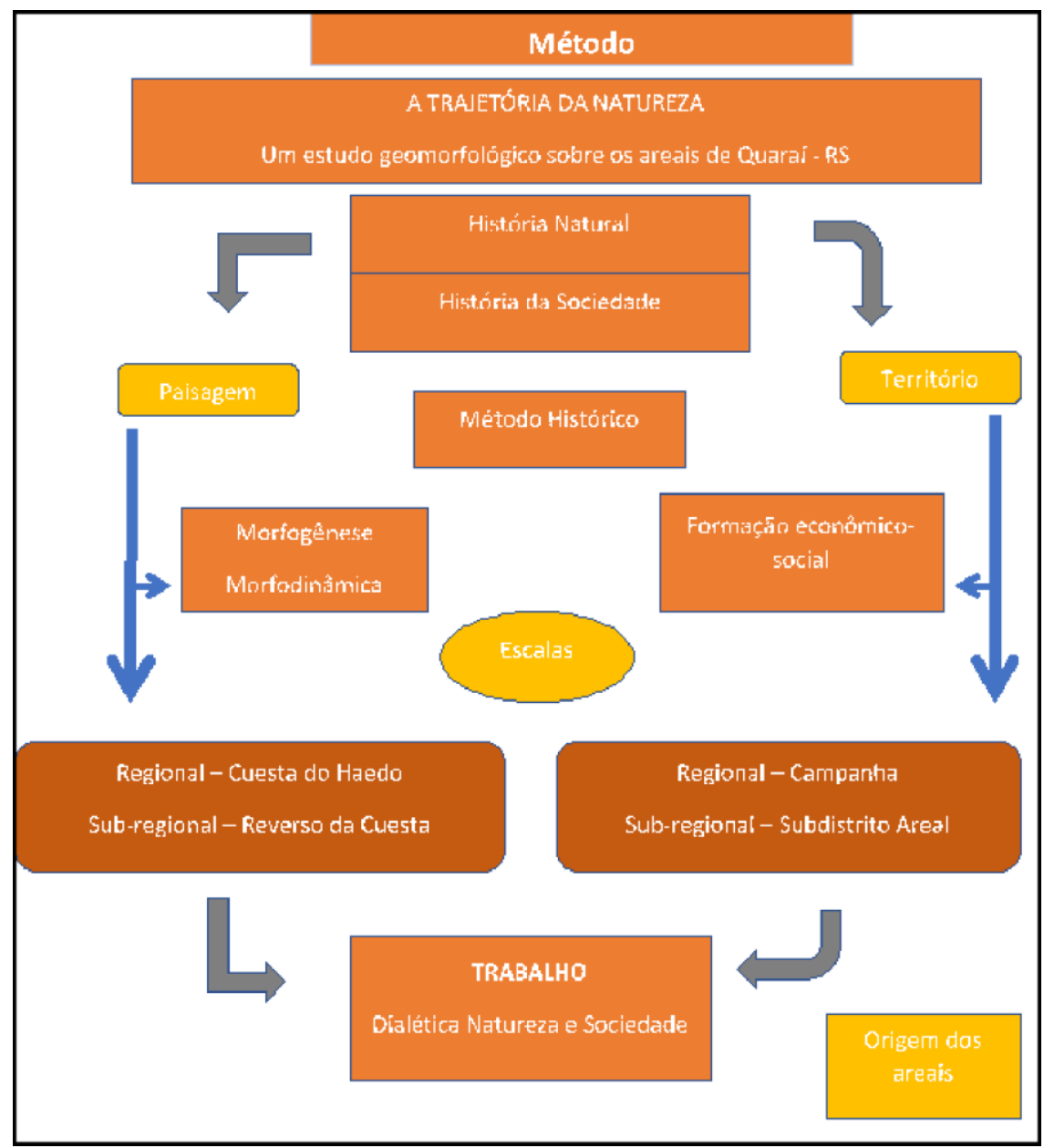

Fonte: Suertegaray (2010).

O produto desta investigação, que considerou a conexão entre diferentes escalas analíticas, em ambos os eixos, foi de que os areais têm origem natural, tendo feito parte da paisagem, antes da incorporação desta ao território em formação. $\mathrm{O}$ trabalho fundado na pecuária extensiva, quando as propriedades ainda não eram delimitadas pelas atuais cercas divisórias, que datam, no estado do Rio Grande do Sul, de 1870, aproximadamente, associada à descrição de viajantes, no primeiros 50 anos do século XIX, que registravam a presença de areias, nessas paisagens, já na época, permitiu a interpretação de que os areais tinham origem natural.

Para além desta interpretação e para compreender a origem e a dinâmica atual dos areais, a pesquisa aprofundou os estudos relativos à paisagem natural (TROLL, 1982), a partir da geomorfologia. Sob está lógica, a tese explica a gênese natural dos areais, identificando uma interação de processos hídricos e eólicos, na remoção de 
depósitos arenosos não consolidados de origem eólica (identificados como unidade B - aqui, identificados como Unidade Areal) sobrepostos à unidade A (aqui, denominados Unidade Cati), constituídos de depósitos arenoso-argilosos de origem fluvial, associados à Formação Botucatu.

Diante dos recursos técnicos, à época da pesquisa, esses depósitos foram datados aproximadamente, considerando suas posições estratigráficas, em Pleistoceno, na Unidade Cati (A), e em Holoceno, na unidade Areal (B). Esta, por sua vez, expressando, na sua constituição, a ação de processos de um clima mais seco do que o atual, em período anterior aos 3000AP, indicado como o período de umidificação, que persiste de forma semelhante, até os dias atuais (BELLANCA, 2001). Esta umidificação promoveu, em alguns lugares, a associação de um conjunto de fatores que deram origem aos areais.

Entre os fatores associados à formação de areais, na área de estudo, foram considerados o tipo de depósito arenoso e friável; a posição destes em rampas associadas a patamares rochosos ou escarpas de relevos isolados; e a constituição de cabeceiras de drenagem em altitudes mais elevadas, sobretudo, nas escarpas de montante e/ou nas vertentes médias de colinas. Estas evidências foram, posteriormente, registradas em outras áreas estudadas, nos municípios de Manoel Viana e de São Francisco de Assis.

O método estruturado para a investigação contemplou: a interpretação da gênese dos areais, no contexto de sua formação, e a dinâmica atual da paisagem; e, sobretudo, permitiu a construção do conceito de Arenização, juntamente com a explicação desta dinâmica. Da mesma forma, permitiu compreender a origem natural dos areais, estabelecida na conexão entre o uso da terra e o trabalho envolvido, quando do transcurso da história de inclusão desta paisagem, no território nacional. (SUERTEGARAY, 1987)

Cabe ressaltar que o conceito central desta análise se baseou na categoria natureza, analisada, de um lado, de forma independente e, de outro, em articulação com a sociedade, nas suas especificidades locais, sem deixar de considerar estas como associadas às políticas imperiais de apropriação política deste espaço, 
tornando, assim, estes processos os originários de inserção desta paisagem ao território nacional.

Embora a tese tenha se colocado no sentido de decifrar uma questão ambiental, não tratou essas áreas com ocorrência de areais como áreas degradadas, considerando-as áreas frágeis, do ponto de vista da dinâmica natural. Não obstante as causas originais serem naturais, o indicativo de degradação do solo foi posteriormente assimilado, uma vez que, no entendimento dos proprietários locais, os areais constituíam terras improdutivas para o uso da terra, na atualidade.

A pesquisa sobre o tema da Arenização teve continuidade, através do grupo de pesquisa Arenização/desertificação: questões ambientais e incorporou outras áreas com presença de areais, em municípios do Sudoeste do RS. Estas permitiram um aprofundamento da compreensão relativa à dinâmica dos areais e o avanço, na elaboração de uma síntese da constituição dessas feições. Nesse sentido, são expoentes os trabalhos de VERDUM (1997), de SUERTEGARAY, GUASSELLI e VERDUM (2001), de FREITAS (2006), de PIRES (2008), de DA SILVA (2009), de EVERS (2010), de GUSSSELLI et al. (2012) e de SUERTEGARAY (2013).

Na continuidade desta narrativa, a questão que se coloca, em relação a um processo de pesquisa, é PARA QUEM PESQUISAR. Obviamente, num primeiro momento, o objetivo da pesquisa esteve vinculado à decifração de um problema científico. Certamente, este problema derivou de uma discussão já presente, na sociedade gaúcha, e grandemente veiculada pela imprensa regional, como uma questão ambiental de significativas proporções. Diante disto, os resultados da tese, concluída em 1988, foram sendo apropriados por diferentes segmentos sociais e o tema foi colocado em debate, em especial, pelo fato de que a interpretação a que se chegava contrariava o anteriormente posto, para a gênese dos areais, ou seja, seu entendido como processo de desertificação, decorrente do uso inadequado do solo, quando da expansão da lavoura de soja (1970-1985), nos municípios de Alegrete e de São Francisco de Assis, particularmente. 
Este debate se deu em diferentes instâncias e a aceitação não se deu, senão, através de conflitos, não obstante, o PARA QUEM, enquanto resultado de pesquisa, é sintetizado na Figura 3.

Figura 3 - Áreas de diálogo, de debate e/ou de embate, na socialização do conhecimento sobre Arenização

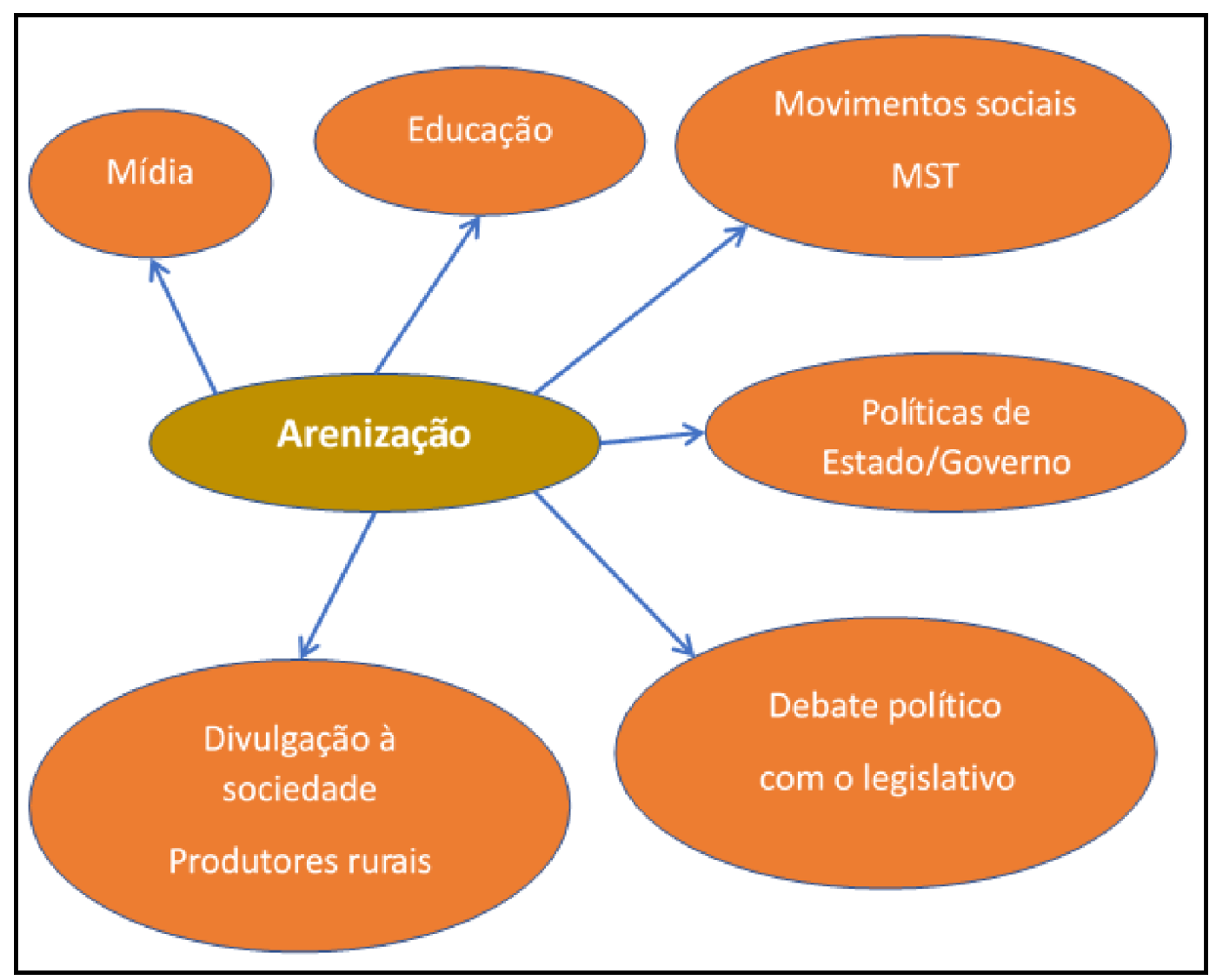

Fonte: Suertegaray (2010).

Esta figura expressa, de maneira sintética, os diferentes agentes envolvidos, ao longo desse percurso, com o tema arenização e indica que, para além da discussão acadêmica e educativa, este tema envolveu diferentes agentes, que se envolveram, na discussão, em tempos diferentes e com interesses, por vezes, antagônicos. Ou seja, o tema arenização ensejou embates entre empresários, sobretudo, os silvicultores, o Estado e suas políticas, em relação a sua metade Sul, o legislativo estadual e os movimentos sociais, sejam o movimento ambientalista ou o Movimento dos SemTerra (MST). Estes exemplos nos permitem refletir sobre o sentido social desta investigação e de seu caráter conflitivo. 
Na sequência das perguntas que norteiam a pesquisa, tem-se, ainda, uma outra pergunta, que se considera da maior importância de discussão, no campo científico contemporâneo. Trata-se de perguntar, ao longo do processo, COM QUEM PESQUISAR. No entendimento expresso nesse texto, temos duas modalidades de resposta: uma, que diz respeito às articulações com outras áreas do conhecimento, para decifrar questões que surgem, ao longo do processo; e, outra, que diz respeito à realização de uma pesquisa em conjunto com a população envolvida no processo de investigação.

Aqui, vamos considerar a primeira possibilidade e explicitar como ela se deu, ao longo desses anos de investigação. A Figura 4 sintetiza esta conexão. Ela expressa um diálogo que foi sendo construído, na medida em que novas questões investigativas surgiam.

Figura 4 - Representação diagramática dos campos de conhecimento em articulação, na pesquisa sobre arenização

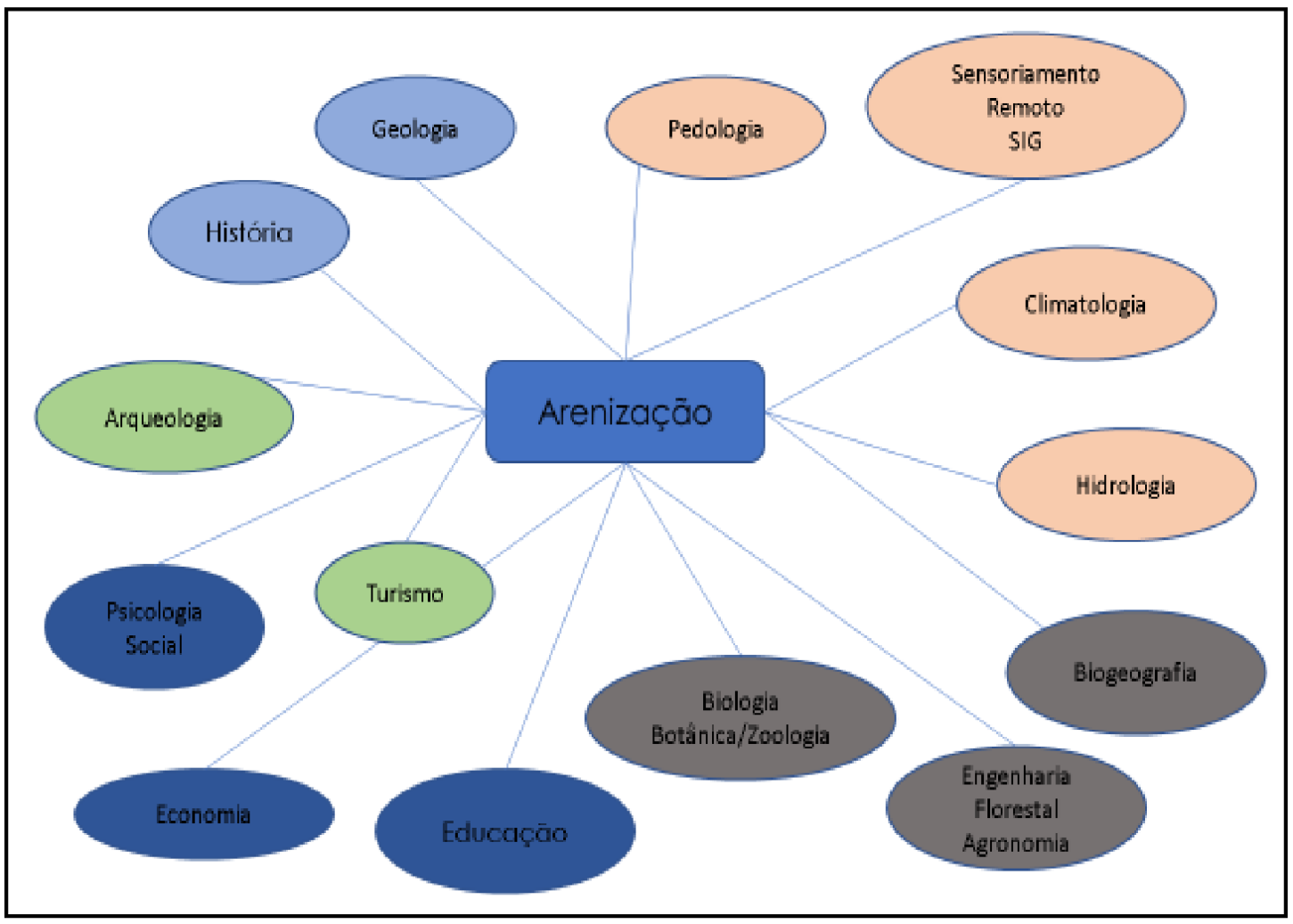

Fonte: Suertegaray (2010). 
O quadro expressa as diferentes áreas de conhecimento que contribuíram para o aprofundamento do tema Arenização, após a constituição do grupo inicial de pesquisa, em 1989. As áreas envolvidas são relacionadas tanto com os estudos da natureza quanto os das humanidades. Aqui, não será descrita a contribuição de cada área. Pretende-se explicar, neste momento, como, a partir desta experiência, chegase a um conhecimento transdisciplinar.

Quando nos referimos à transdisciplinaridade, somos levados a pensar em transcendência, ou seja, em um conhecimento além do disciplinar, que é facilmente reconhecido pelos resultados da investigação sobre Arenização, nesses mais de 30 anos de pesquisa. Entretanto, o aprendizado, nesse processo, diz respeito ao Método. Costuma-se dizer que uma pesquisa com resultados além dos disciplinares exige a construção de um método comum, que agregue todos os participantes. $O$ entendimento, a partir dessa experiência, é de que esta articulação nem sempre é possível, pois cada campo do conhecimento, e, da mesma forma, cada pesquisador, possui construções analíticas diferentes.

Isto posto, o que se considera relevante é conceber transdisciplinaridade, também, como trânsito, ou seja, como a capacidade de transitar em diferentes áreas do conhecimento e buscar compreender o caminho investigativo de cada campo disciplinarmente, considerando-se que, somente diante do colocar-se no lugar do outro, seremos capazes de compreender e de aceitar as contribuições provenientes de outros pesquisadores. Ao compreendê-las, serão mais facilmente feitas, as conexões, em relação aos resultados, e teremos um conhecimento novo, derivado do que se poderia chamar de conhecimento por contradição e por acoplamento, sendo, o acoplamento, entendido como um processo de vinculação ao conhecimento já produzido, que, no processo de pesquisa, permitam um avanço, nas respostas desejadas, expressas sem desconsiderar suas contradições.

Desta forma, se efetivaram as pesquisas, no âmbito do grupo, e, desta forma, a cada pergunta respondida outras tantas questões são construídas. 


\section{CONCEITOS E RESSIGNIFICAÇÕES}

Neste outro momento, trazemos à discussão reflexões sobre alguns conceitos, que, ao longo desta investigação, deram suporte teórico à pesquisa e/ou derivaram de reflexões desta produção.

Faz-se referência, neste texto, às categorias: natureza, espaço, tempo e escala, e aos conceitos de paisagem, de degradação ambiental e de natureza transfigurada.

Ainda que esses conceitos não estejam explicitamente abordados, em grande parte dos resultados de pesquisa divulgados, uma reflexão teórica, ao longo deste processo, permitiu atribuir, no contexto da pesquisa, outras significações, que não se encaixam nas mais correntes.

\subsection{Natureza}

A natureza, como categoria constituinte do espaço geográfico, é considerada externa à sociedade, sendo compreendida como a priori, em que o homem individual ou social tem as possibilidades de reprodução de sua vida. Constitui, na análise geográfica, de maneira ampla, uma externalidade ao social.

Ao longo da investigação, relativa aos areais, a natureza foi assim concebida, e a análise de seus processos de transformação foram centralizados num dos eixos de investigação. Esta perspectiva de distanciamento permitiu a compreensão da dinâmica da natureza e dos processos de arenização, na sua dinâmica própria - a natural. A mediação desta com a dimensão social, através do conceito de trabalho permitiu interpretar a formação dos areais, na área em estudo, como natural. Ou seja, a mediação com o social não vincula esses processos, na origem, a uma gênese antrópica.

Esta concepção de natureza levou a uma busca de conceituação, chegando-se, após mais algum tempo, ao entendimento de que a natureza é tudo aquilo que se origina e se transforma, ao longo do tempo, sem intencionalidade humana, inclusive, no próprio homem, enquanto ser biológico. 
Não obstante, se reconhece que o trabalho, enquanto mediador da natureza e da sociedade, promove a constituição de uma natureza que se denominou de transfigurada. O termo transfiguração indica que, embora ocorra transformações, nas formas e nos processos naturais, estes a modificam, mas não a anulam. Ou seja, dialeticamente, a natureza natural está presente, na natureza transformada; neste, sua presença é transfigurada.

\subsection{Tempo-espaço}

A construção metodológica assumida incorpora a dimensão espaço-tempo, enquanto processo/movimento, o que significou enfatizar, ao longo de formação da história da natureza, naquilo que foi possível evidenciar, como esta se transformou e, nessa transformação, deu origem aos areais.

Merece destaque, aqui, uma distinção metodológica: na época da construção desta investigação, não se optou pela compreensão sistêmica, seja da natureza, seja da sociedade; a ideia era a de compor uma análise do espaço geográfico. A razão disto se deve ao fato de que o sistemismo se constituía, basicamente, na busca de uma compreensão da totalidade sincrônica, ou seja, no entendimento da funcionalidade da natureza e/ou da natureza e da sociedade, em suas conexões.

Espaço e tempo, portanto, ainda que compreendidos separadamente, se revelam coexistentes. E, na pesquisa relativa aos areais, isto fica evidente, quando os estudos indicam a presença de artefatos arqueológicos, líticos, boleadeiras e cerâmicas. Estes revelam tempos diferentes de populações pré-colombianas, habitando o lugar, além de demonstrarem a ocorrência de areais, em tempos remotos (pelo menos, 12000AP).

Estes dados permitem pensar que esta paisagem, ainda com forte atuação dos processos naturais, registrou a presença humana e seu trabalho, desde tempos remotos, quando foram habitadas pelos pampianos.

\subsection{Paisagem e degradação do solo/ambiental}


Os registros arqueológicos (MILER, 2000; BELLANCA, 2001) encontrados contemporaneamente explicitam, o que já referia Santos (2006; 2012), que a "paisagem é uma acumulação desigual de tempo" (SANTOS, 2006; 2012). Ou seja, na paisagem, passado e presente coexistem.

A presença humana e o uso desta paisagem, enquanto possibilidade de exploração de recursos, se expressa em cada época de forma diferente, sendo esta mediação pelo trabalho o que indica a dimensão do que se denomina, hoje, degradação de solo e/ou, de forma mais ampla, degradação ambiental.

Ao se fazer referência aos areais e a sua origem, ao longo desses anos de pesquisa, chegou-se a identificar esses processos como de degradação do solo. As pesquisas que se sucederam, no entanto, contribuíram para fortalecer o conceito da gênese natural desses areais.

Figura 5 - Processo de arenização e de formação de areais, no Município de Maçambara, RS

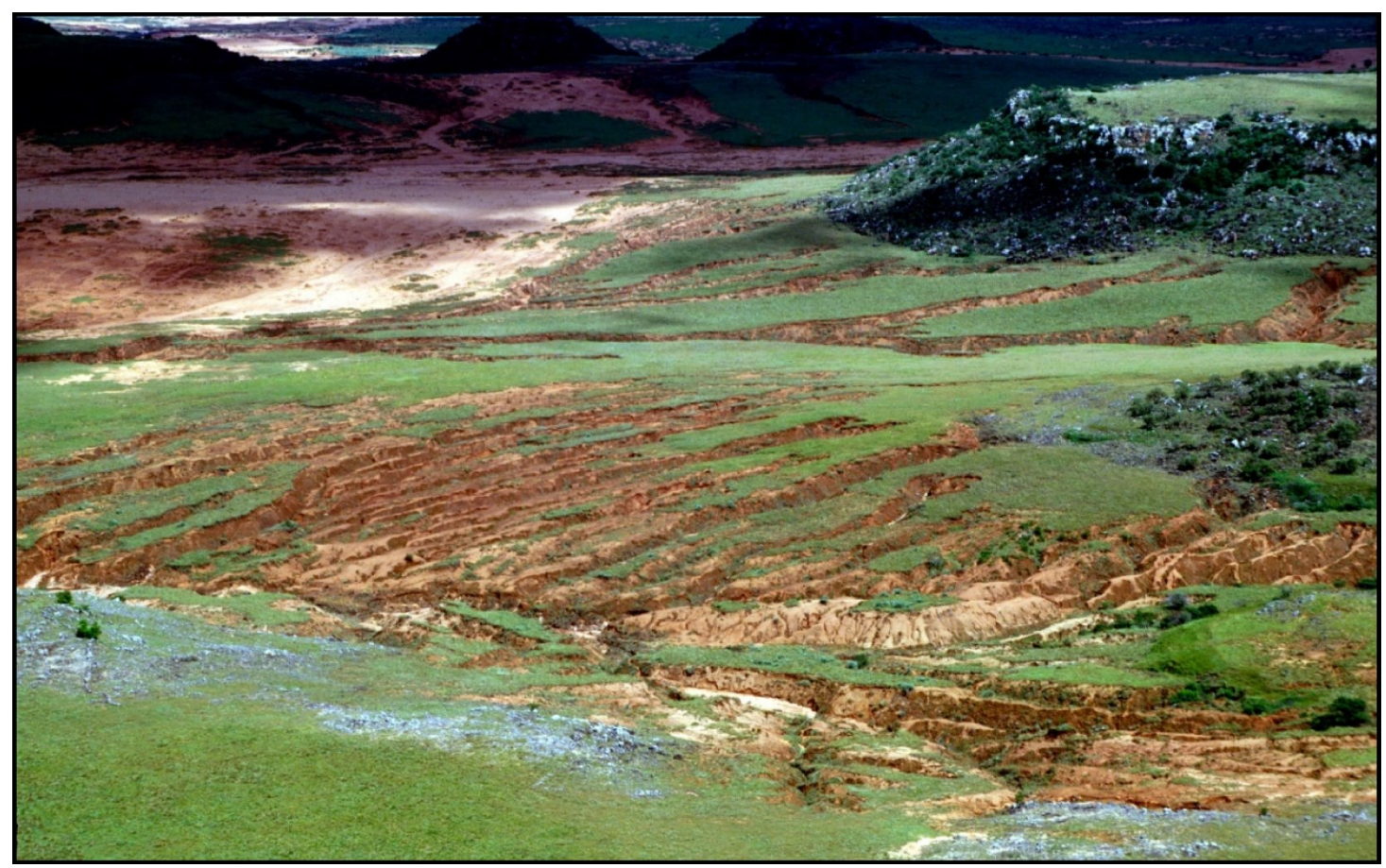

Fonte: Suertegaray, Guasselli e Verdum (2001).

Sobretudo, os estudos e Bellanca (2001) e Bellanca e Suertegaray (2013), derivados da análise arqueológica de sítios indígenas, nos areais de Quaraí, 
primeiramente, por Milder (2000), além dos estudos, na área da Biologia, a partir da fauna e de flora presentes, nessas áreas, por Freitas (2006) e Silva (2009), na área da Botânica, permitem colocar outra questão: sendo os areais, pelo menos, áreas historicamente registradas, naturais, seriam estas áreas solos degradados ou estas decorrem de uma evolução, na qual os processos naturais de intensa erosão estão presentes, promovendo essa dinâmica?

Uma reflexão se faz necessária: a degradação dos solos é um conceito relacionado à possibilidade de uso deste recurso. Mais do que isso, diz respeito ao valor de troca deste recurso, uma vez que os proprietários extraem produtos dessas terras e os comercializam. Portanto, se o processo é natural, e assim ele é concebido, não teríamos degradação de solo/ambiente.

O processo de arenização seria, então, compreendido como vinculado à dinâmica da natureza, na sua continua transformação, o que quer dizer que, ao denominarmos degradação do solo, nossa referência está implicada ao uso social da natureza e tal definição demonstra essa relação, ou seja, a natureza degradada remete ao uso e ao valor social da natureza.

Não obstante outros usos, mais recentemente trazidos ao debate, trata-se de pensar para além do valor do solo, em si, ou do solo e das pastagens; trata-se de pensar a paisagem como valor estético e, nesse sentido, aos areais têm sido sugeridos como áreas patrimoniais (Suertegaray (2010) e Vieira e Verdum (2019)).

\subsection{Escala}

A escala de análise ultrapassa a escala cartográfica, na relação com o terreno. Aqui, ao se referir à escala, adentra-se na discussão da pesquisa relativa à explicação científica. O que se quer dizer é que, ao investigar a gênese dos areais, foi necessário transitar em diferentes escalas: a local, a regional e a nacional e além desta (a global), no âmbito da análise social. Na perspectiva dos estudos da natureza, tratou-se, também, a análise sob diferentes escalas, desde a micro até a macro, a partir de inferências, de comparações e de deduções. Esta prática operacional vem sendo discutida, mais recentemente, na Geografia, indicando a conexão das escalas como 
um caminho possível, na busca da totalidade, no campo dos estudos da natureza, seria a constituição de leis de explicação do fenômeno.

Ao que se chega, através destas conexões, em relação à arenização, não é, necessariamente, à constituição de leis: compreende-se que se buscou uma análise que fosse mais totalizante e que, nesse processo de totalização, fossem levados em conta a natureza e a sociedade em seu movimento.

Esse movimento é contínuo e, diante deste processo, outras questões, relacionadas aos areais e à arenização, surgem, sejam de ordem da decifração da dinâmica da natureza, sejam em relação aos novos usos dessa região, a exemplo da silvicultura e da expansão da soja (SUERTEGARAY, MORELLI, 2010; MORELLI, 2011).

Em qualquer dimensão, seja nos estudos da natureza, seja nos estudos sociais, as escalas de análise exigem uma conexão para a compreensão do que se estuda. As pesquisas sobre os areais e sobre a arenização constituem exemplos destas práticas de análise.

\section{NA CONTINUIDADE, UMA AGENDA POSSÍVEL}

Diante do exposto e considerando os estudos mais recentes, em relação aos areais do Sudoeste do RS e, em particular, aos areais do município de Quaraí, bem como considerando trabalhos de campo, realizados nos últimos anos, indicam-se alguns temas passiveis de investigação.

O primeiro deles se refere à continuidade dos estudos de explicação da gênese dos areais e, mais especificamente, à datação dos depósitos, nos quais ocorre o processo de arenização, objetivando uma compreensão paleo-ambiental da área. Datações com métodos não acessíveis, no ano em que a pesquisa foi iniciada (1983), hoje, estão mais acessíveis e constituem caminhos, no âmbito da geomorfologia, na atualidade. Tais estudos já iniciaram, com a tese de Mateus G. Oliveira (2017), em andamento. 
O aprofundamento, na dinâmica dos areais, sobretudo, na cidade de Quaraí, em que estes se configuram diferentemente dos areais de outras regiões do Sudoeste do RS, com a presença de cascalheiras, recobrindo grandes extensões do topo da formação Botucatu, hoje, aflorante, no interior dos areais, em maiores dimensões do que já tinha sido observado e relatado, em Suertegaray (1987).

A explicação das superfícies, no topo aflorante da Formação Botucatu (Figura 6a) (com base na teoria da etchplanação (VITTE, 2001), visando uma compreensão de um provável e longo período de exumação do material de cobertura anterior à formação das unidades Cati (A) e Areal (B), como produtos de depósitos, sob condições de clima mais úmidos e mais secos, sucessivamente, em períodos mais atuais, sobre essas superfícies com registros de climas secos, como os ventifactos (Figura 6b).Ou seja, seixos, cascalhos e mesmo matacões de diferentes dimensões resultantes da corrosão eólica, resultando em formas facetadas. A presença destas feições são indicativos de erosão eólica em condições de clima seco onde atuam fortes ventos.

Figura 6 - Superfície do topo da Formação Botucatu, exumada, após transporte de sedimentos da Unidade B (Unidade Areal) - Quaraí/RS

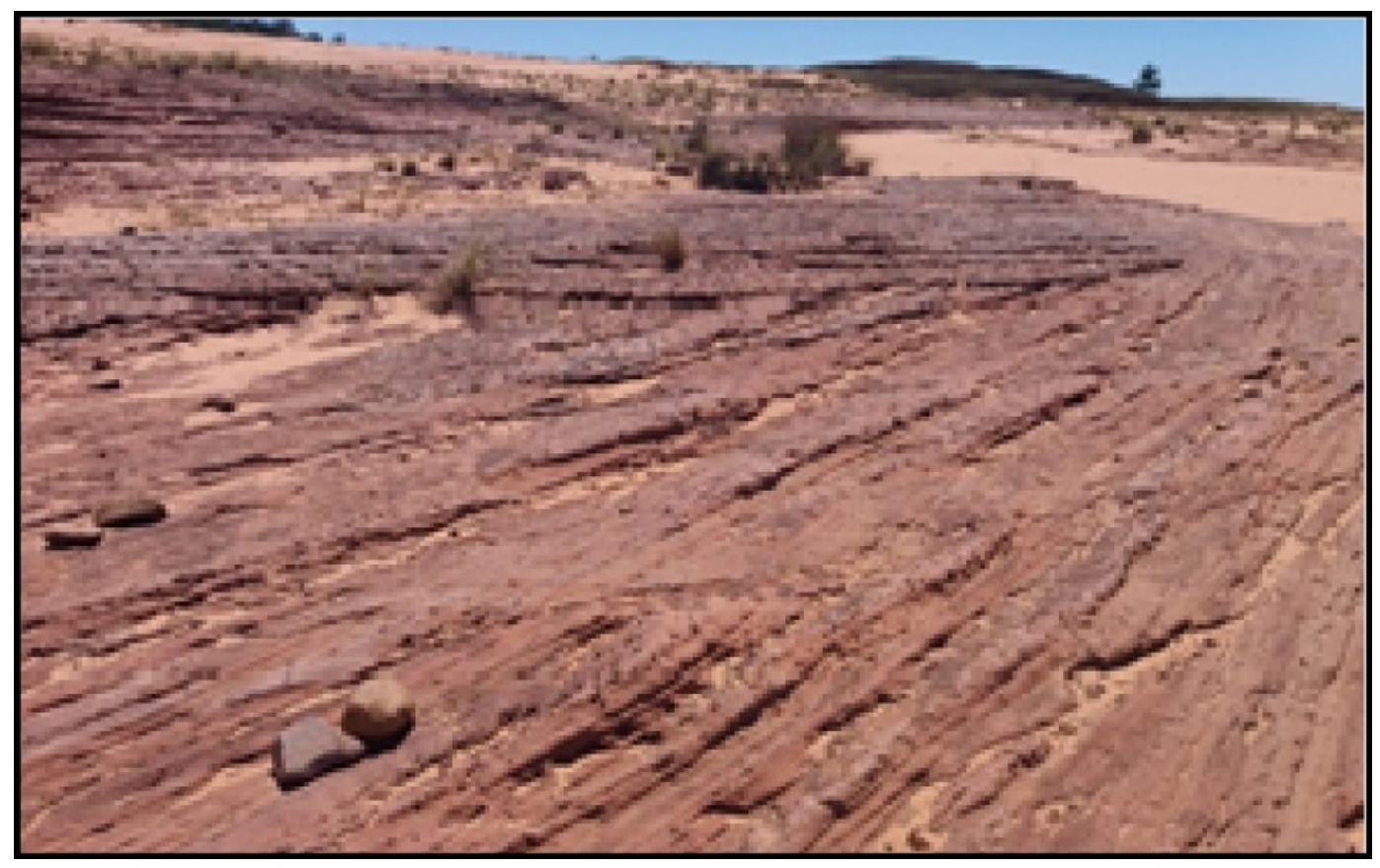

Fonte: acervo pessoal de Dirce Suertegaray (2017). 
Figura 7 - Ventifacto sobre arenitos da Formação Botucatu - Quaraí/RS

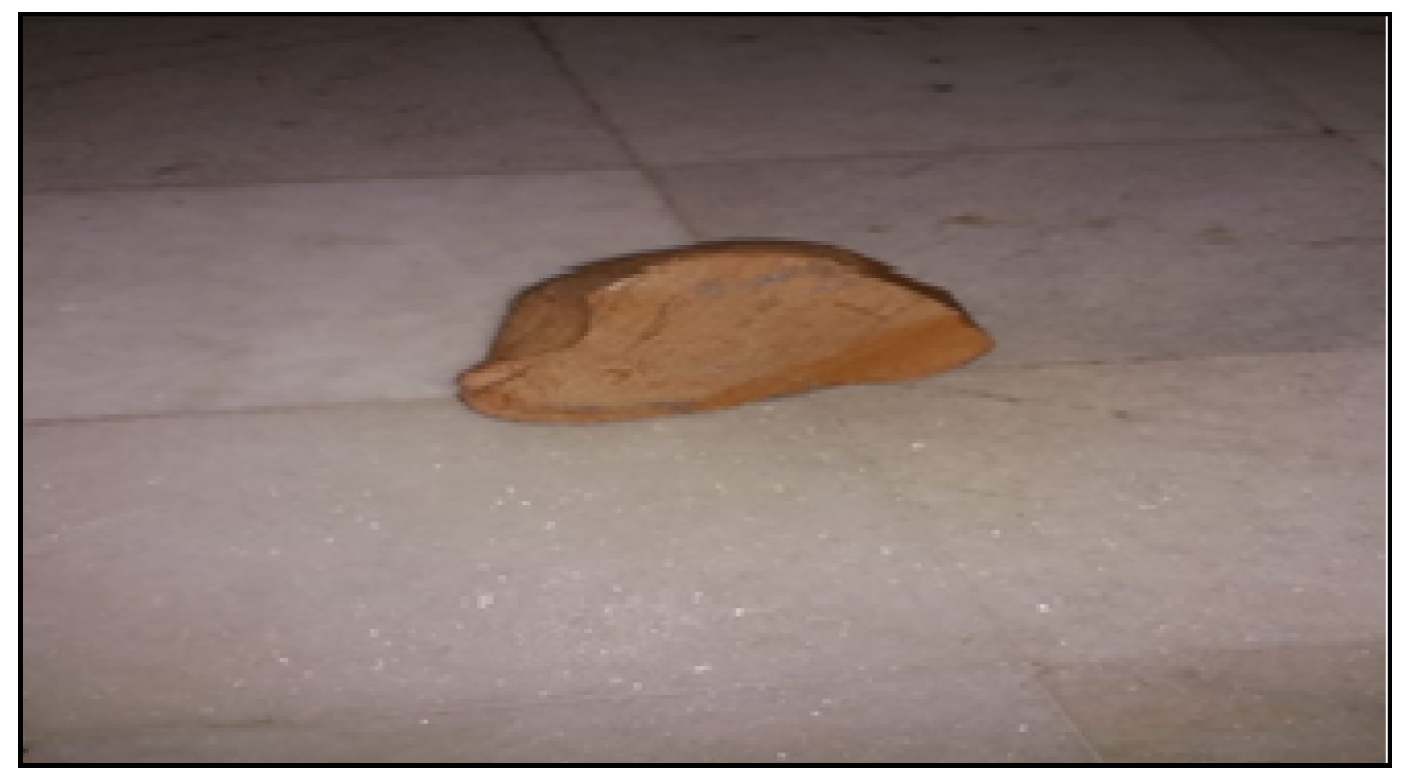

Fonte: acervo pessoal de Dirce Suertegaray (2017).

Sob uma perspectiva geomorfológica, considero serem estes alguns pontos que emergem, nesse momento, como questões a serem investigadas.

\section{CONCLUSÕES}

Ao finalizar este relato reflexivo sobre a pesquisa, relativa aos areais/arenização, na relação com a Geografia, tem-se que:

-A busca, desde a fase inicial da pesquisa sobre os areais, foi por promover um estudo que tivesse, como pressupostos, alguns princípios da análise geográfica, que, hoje, são pouco discutidos, mas que são inerentes aos estudos geográficos, ou seja, localização, distribuição, analogia/comparação e conexão.

•estudo da relação natureza e sociedade, ou seja, da busca de unidade, na Geografia, a ser construída, através da articulação dos conceitos de Paisagem e de Território.

-A localização do fenômeno estudado e a sua investigação considerando os constituintes locais. Neste sentido, a pesquisa, junto aos areais, constituiu o marco inicial. 
•A distribuição e extensão desses areais, a comparação entre essas formas e suas localizações, considerando a ação de processos externos, sobretudo, as dinâmicas hídrica e eólica, em relação à forma do relevo.

-As conexões entre diferentes dimensões do objeto de estudo, naturais e/ou sociais, considerando essas conexões em diferentes escalas e entre escalas.

-A construção de uma síntese explicativa para a gênese dos areais de Quaraí, que se constituiu, do ponto de vista geomorfológico, a referência interpretativa que embasou estudos em outras áreas, tendo sido, este mesma sintese, através de estudos interdisciplinares, ampliado.

\section{REFERÊNCIAS}

BELLANCA ET. Uma contribuição para a explicação da gênese dos areais do Sudoeste do Rio Grande do Sul [dissertation] Porto Alegre: Programa de Pós-Graduação em Geografia/UFRGS; 2001. 87 p.

BELLANCA ET, SUERTEGARAY DMA. Sítios Arqueológicos e Areais no Sudoeste do Rio Grande do Sul. Mercator, Fortaleza, v. 4, p. 99-114, 2003.

DA SILVA LAP. Paisagens dos Areais Gaúchos. Conectividades e vivências, caminhando em busca de uma hermenêutica Instauradora à Educação Ambiental [dissertation]. Porto Alegre: Programa de Pós-Graduação em Geografia/UFRGS; 2008. 155 p.

FREITAS EM. Arenização e Fitossociologia da Vegetação de Campo no Município de São Francisco de Assis, RS [dissertation]. Porto Alegre: Programa de Pós-Graduação em Geografia/UFRGS; 2006. 139 p.

MARX K, ENGELS F. A ideologia alemã. Bruni JC e Nogueira MA, tradutores. São Paulo: Grijaldo; 1977.

MILDER, S. Arqueologia do Sudoeste do Rio Grande do Sul: uma perspectiva geoarqueológica [thesis]. São Paulo: Faculdade de Filosofia, Letras e Ciências Humanas/USP; 2000. 174 p.

MORELLI, LA. Monocultura do eucalipto e as implicações territoriais: uma constituição oligopolista na Metade Sul do Rio Grande do Sul [thesis]. Porto Alegre: Programa de Pós-Graduação em Geografia/UFRGS; 2011. 222 p. 
OLIVEIRA M, SUERTEGARAY DMA. Paleogeografia da área de ocorrência de areais. In: Suertegaray DMA, Da Silva LAP, Guasselli LA, editors. Arenização natureza socializada. Porto Alegre: Compasso Lugar Cultura/Imprensa Livre; 2013. p. 201-26.

SANTOS M. A Natureza do espaço: técnica e tempo, razão e emoção do espaço. 4th ed. 2nd print. São Paulo: Editora da Universidade de São Paulo; 2006. 259 p.

SANTOS M. Pensando o Espaço do Homem. 5th ed. 3rd print. São Paulo: Editora da Universidade de São Paulo; 2012. 96 p.

SOUTO JJP. Deserto, uma ameaça? Estudos dos núcleos de desertificação na fronteira sudoeste do Rio Grande do Sul. Porto Alegre: Secretaria da Agricultura Departamento de Recursos Naturais Renováveis; 1985. 169 p.

SUERTEGARAY DMA. A Trajetória da Natureza: um estudo geomorfológico sobre os areais de Quarai-RS [thesis]. São Paulo: Faculdade de Filosofia, Letras e Ciências Humanas/USP; 1987. 243 p.

SUERTEGARAY DMA, GUASSELLI LA, VERDUM R, editores. Atlas da Arenização, Sudoeste do Rio Grande do Sul. Porto Alegre: Secretaria da Coordenação e Planejamento e Secretaria de Ciência e Tecnologia, Governo do Estado do Rio Grande do Sul; 2001.85 p.

SUERTEGARAY DMA, GUASSELLI LA, ANDRADES FILHO CO. Influencia morfoestructural en la génesis de los procesos de arenización en Rio Grande do Sul, Brasil. Revista de Geografía Norte Grande. 2008;39:59-72.

SUERTEGARAY DMA, MORELLI LA. Conflitos da Silvicultura em áreas em processo de arenização, Sudoeste do Rio Grande do Sul. In: Moreira E, Targino I, editors. Desertificação, desenvolvimento sustentável e agricultura familiar: recortes no Brasil, em Portugal e na África. João Pessoa: Editora da Universidade das Paraíba/Brasília: Ministério do Meio Ambiente; 2010. 344 p.

SUERTEGARAY DMA, MORELLI LA. Arenização e monocultura do eucalipto no Sudoeste (sw) do Rio Grande do Sul. RevAGB [Internet]. 2011 [cited 2019 out 03];(14):59-82. Avaliable from: https://periodicos.ufms.br/index.php/RevAGB/article/view/616/416.

TROLL C. El paisage geográfico y su investigación. In: Mendonza JG, Jimenez JM, Contero N, editors. El pensamiento geográfico. Estudio interpretativo y antologia de textos (de Humboldt a las tendências actuales). Madrid: Alianza Editorial; 1982. p. 3239.

VERDUM R. [Geographical approach to "deserts" in the municipalities of São Francisco de Assis and Manuel Viana, State of Rio Grande do Sul, Brazil] [Thesis]. Toulouse: Université de Toulouse II - Le Mirail/UTH; 1997. 211 p. French. 
VIEIRA LFS, VERDUM R. A Proteção da Natureza e do Patrimônio da Humanidade pela Beleza Cênica da Paisagem. La protection de la nature et du patrimoine de l'humanité par la beauté scientifique du paysage. The protection of the nature and heritage of humanity by the scientific beauty of the landscape. Confins. 2019; (2019):1-18.

VITTE AC. Considerações sobre a teoria da etchplanação e sua aplicação nos estudos das formas de relevo nas regiões tropicais quentes e úmidas. Terra Livre. 2001;(16):11-24. 